\title{
PENGARUH BUDAYA ORGANISASI, DISIPLIN KERJA, DAN KEPUASAN KERJA TERHADAP KINERJA KARYAWAN NON MEDIS RUMAH SAKIT ISLAM MALANG
}

\author{
ANY ISVANDIARI \\ DOSEN DPK JURUSAN MANAJEMEN STIE ASIA MALANG \\ ANANG PURWANTO
}

\begin{abstract}
The research was purposed to find out whether there was any partial or simultaneous effects of organizational culture, work discipline, and job satisfaction toward the work performance of non-medical employees at Malang Islamic Hospital.

The population of this research is 93 non-medical employees and 62 are selected as sample. Sampling technique used is purposive sampling of non-medical employees which already a permanent employees. Data analysis was made with multiple regression analysis.

Analysis result show that organizational culture, work discipline, and job satisfaction have any partial and simultaneous effects toward the performance of non-medical employees at Malang Islamic Hospital.

Key word : organizational culture, work discipline, job satisfaction, work performance.
\end{abstract}

\section{ABSTRAKSI}

Penelitian ini bertujuan untuk mengetahui pengaruh secara parsial maupun simultan variabel budaya organisasi, disiplin kerja dan kepuasan kerja terhadap kinerja karyawan non medis Rumah Sakit Islam Malang.

Populasi dari penelitian ini adalah 93 karyawan non medis dan jumlah tersebut 62 responden terpilih sebagai sampel. Tehnik sampel yang digunakan adalah purposive sampling yaitu karyawan non medis yang berstatus sebagai karyawan tetap. Metode analisis yang digunakan adalah analisis regresi berganda.

Hasil penelitian menunjukkan bahwa secara parsial dan simultan budaya organisasi, disiplin kerja dan kepuasan kerja berpengaruh terhadap kinerja karyawan non medis Rumah Sakit Islam Malang.

Kata kunci: Budaya organisasi, disiplin kerja, kepuasan kerja, kinerja karyawan. 


\section{PENDAHULUAN}

Kesehatan bagi masyarakat telah menjadi suatu kebutuhan utama. Kebutuhan yang dimaksud adalah kebutuhan untuk mendapatkan pelayanan kesehatan yang layak, seiring dengan meningkatnya taraf hidup masyarakat maka semakin meningkat pula tuntutan masyarakat dan nilai-nilai kesehatan, salah satu lembaga kesehatan adalah rumah sakit. Fungsi rumah sakit dewasa ini bertambah ke arah pelayanan kesehatan yang menyeluruh seiring dengan berkembangnya ilmu dan teknologi baik dalam upaya penyembuhan bagi masyarakat yang sedang sakit maupun bagi pasien yang membutuhkan konsultasi kesehatan dan upaya pencegahan peningkatan kesehatan.

Di dalam sebuah rumah sakit pengelolaan sumber daya dengan baik akan berpengaruh terhadap kelangsungan hidup rumah sakit, karena dengan buruknya sumber daya yang ada dalam rumah sakit, maka rumah sakit tersebut tidak dapat berjalan sebagaimana mestinya.

Menurut Setiawan dan Waridin (dalam M. Hanif Al Rizal, 2012) kinerja karyawan merupakan hasil atau prestasi kerja karyawan yang dinilai dari segi kualitas maupun kuantitas berdasarkan standar kerja yang ditentukan oleh pihak organisasi.

Budaya organisasi merupakan sistem penyebaran kepercayaan dan nilai-nilai yang berkembang dalam suatu organiasi dan mengarahkan perilaku anggota-anggotanya.

Menurut Robbin (1998; dalam M. Hanif Al Rizal, 2012) yang mendefinisikan budaya organisasi (organizational culture) sebagai suatu sistem makna bersama yang dianut oleh anggota-anggotanya dan yang membedakan organisasi tersebut dengan organisasi yang lain.

Disiplin kerja adalah suatu alat yang digunakan para manajer untuk berkomunikasi dengan karyawan agar mereka bersedia untuk mengubah suatu perilaku serta sebagai suatu upaya untuk meningkatkan kesadaran dan kesediaan seseorang mentaati peraturan perusahaan dan norma-norma sosial yang berlaku (Rivai dalam Dipta Adi Prawatyo 2012).

Menurut Heni Handoko (dalam M. Hanif M. Rizal 2012) menyatakan kepuasan (job satisfaction) adalah keadaan emosional yang menyenangkan atau tidak menyenangkan atas suatu pekerjaan. Kepuasan kerja mencerminkan perasaan seseorang terhadap pekerjaannya dan nampak dalam sikap positif karyawan terhadap pekerjaan dan kepada sesuatu yang dihadapi di lingkungan kerjanya.

Rumah Sakit Islam Malang adalah rumah sakit swasta yang dimiliki oleh Yayasan Universitas Islam Malang yang berlokasi di Jalan MT. Haryono no. 139 Malang. Sejak beroperasinya rumah sakit ini pada tanggal 10 Juni 1998 oleh Departemen Kesehatan Republik Indonesia, mengalami perkembangan menjadi Rumah Sakit tipe B pendidikan. Permasalahan yang dihadapi Rumah Sakit Islam Malang adalah masih kurangnya tingkat kedisiplinan, budaya organisasi dan kepuasan kerja dari karyawan non medis sehingga tentu akan mempengaruhi kinerjanya.

Sebagaimana perjelasan diatas, maka dapat ditarik rumasan masalah sebagai berikut :

1. Apakah ada pengaruh secara parsial antara budaya organisasi, disiplin kerja dan kepuasan kerja terhadap kinerja karyawan non medis Rumah Sakit Islam Malang ?

2. Apakah ada pengaruh secara simultan antara budaya organisasi, disiplin kerja dan kepuasan kerja terhadap kinerja karyawan non medis Rumah Sakit Islam Malang?

\section{LANDASAN TEORI}

\section{BUDAYA ORGANISASI}

1. Pengertian Budaya Organisasi

Organisasi merupakan kumpulan dari sejumlah orang sebagai anggota organisasi, termasuk di dalamnya para pemimpin (manajer) yang artinya setiap hari saling berinteraksi satu sama lain, baik dalam melaksanakan pekerjaan maupun kegiatan lain di luar pekerjaan.

Interaksi itu dapat bersifat formal dan informal, hanya akan berlangsung harmonis dalam arti efektif dan efisien apabila setiap anggota organisasi menerima, menghormati dan menjalankan nilai-nilai atau norma norma sebagai bentuk budaya manusia itu hidup dan berkembang secara dinamis sesuai dengan kondisi organisasi dan menjadi kendali cara berpikir, bersikap dan berperilaku hidup bersama dalam kebersamaan sebagai sebuah organisasi. Nilai-nilai atau norma-norma itulah yang kemudian menjadi budaya organisasi.

Menurut Rivai (2011 : 374) menyatakan : "Budaya organisasi adalah kerangka kerja yang menjadi pedoman tingkah laku seharihari dalam membuat keputusan untuk karyawan dan mengarahkan tindakan mereka untuk mencapat tujuan organisasi budaya harus sejalan dengan tindakan organisasi pada bagian lain seperti perencanaan, pengorganisasian, kepemimpinan dan pengendalian.

Menurut Kreitnee dan Kinicki (2005:79) budaya organisasi adalah suatu wujud anggapan yang dimiliki, diterima secara implisit oleh kelompok dan menentukan bagaimana kelompok tersebut merasakan, memikirkan, dan bereaksi terhadap lingkungannya yang beranekaragam.

2. Karakterik Budaya Organisasi

Robbin (2006 : dalam partiwi 2012) memberikan karakteristik berbudaya organisasi antara lain sebagai berikut :

1. Inisiatif Individu yaitu sejauh mana organisasi memberikan kebebasan kepada setiap pegawai dalam mengemukakan pendapat atau ide-ide yang di dalam pelaksanaan tugas dan fungsinya inisiatif individu tersebut perlu dihargai oleh kelompok atau pimpinan suatu organisasi sepanjang menyangkut ide untuk 
memajukan dan mengembangkan organisasi.

2. Toleransi terhadap tindakan resiko yaitu sejauh mana dianjurkan untuk dapat bertindak agresif, inovatif dan mengambil resiko dalam mengambil kesempatan yang dapat memajukan dan mengembangkan organisasi. Tindakan beresiko yang dimaksud adalah segala akibat yang timbul dari pelaksanaan tugas dan fungsi yang dilakukan oleh pegawainya.

3. Pengarahan yaitu sejauh mana pimpinan suatu organisasi dapat menciptakan dengan jelas sasaran dan harapan yang diinginkan, sehingga para pegawai dapat memahaminya dan segala kegiatan yang dilakukan pada pegawai mengarah pada pencapaian tujuan organisasi.

4. Integrasi yaitu sejauh mana suatu organisasi dapat mendorong unit-unit organisasi untuk bekerja dengan cara yang berkoordinasi.

5. Dukungan manajemen yaitu sejauh mana para pimpinan organisasi dapat memberikan komunikasi atau arahan, bahkan minta dukungan yang jelas terhadap pegawai.

6. Kontrol yaitu adanya pengawasan dari pimpinan terhadap para pegawai dengan menggunakan peraturan-peraturan yang telah ditetapkan demi kelancaran organisasi

7. Sistem imbalan yaitu sejauh mana alokasi imbalan (seperti kenaikan gaji, promosi dan sebagainya) didasarkan atas prestasi kerja karyawan.

8. Toleransi terhadap konflik yaitu sejauh mana para pegawai didorong untuk mengemukakan konflik dan kritik secara terbuka guna memajukan organisasi dan bagaimana pula tanggapan organisasi terhadap konflik tersebut.

9. Pola komunikasi yaitu sejauh mana komunikasi dalam organisasi yang dibatasi oleh hierarki kewenangan yang formal dapat berjalan baik.

\section{DISIPLIN KERJA}

1. Pengertian disiplin kerja

Menurut Rivai (2004:444) disiplin kerja adalah suatu alat yang digunakan para manajer untuk berkomunikasi dengan karyawan agar mereka bersedia untuk mengubah suatu perilaku sebagai suatu wilayah untuk meningkatkan kesadaran dan ketersediaan seseorang mentaati semua peraturan perusahaan dan norma-norma sosial yang berlaku

2. Indikator Disiplin Kerja

Menurut Malayu Hasibuan (2010) indikator disiplin kerja adalah :

a. Memahami semua peraturan perusahaan

b. Penggunaan waktu secara efektif

c. Tanggung jawab di dalam pekerjaan dan tugas

d. Tingkat absensi

\section{KEPUASAN KERJA}

1. Pengertian Kepuasan Kerja

Menurut Hani Handoko (2001) kepuasan kerja (job satisfaction) adalah keadaan emosional yang menyenangkan atau tidak menyenangkan atas sesuatu pekerjaan. Sedangkan menurut Robbins (2002:26) mendefinisikan kepuasan kerja adalah suatu sikap umum seseorang individu terhadap pekerjaannya.

Kepuasan kerja karyawan harus diciptakan sebaik-baiknya supaya moral kerja, dedikasi, kecintaan dan kedisiplinan karyawan meningkat.

2. Indikator Kepuasan Kerja

$$
\text { Menurut Luthans (2006) }
$$
menyebutkan bahwa indikator yang dapat mempengaruhi kepuasan kerja adalah:

a. Tingkat upah dan gaji yang diterima

b. Pekerjaan itu sendiri

c. Rekan kerja

d. Promosi karir

e. Kepenyeliaan (supervisi)

\section{KINERJA KARYAWAN}

1. Pengertian Kinerja

$$
\text { Menurut }
$$

Mangkunegara (2002:22) kinerja adalah hasil kerja baik secara kualitas dan kuantitas yang dicapai oleh seseorang pegawai dalam melaksanakan tugasnya sesuai dengan tanggung jawab yang diberikan padanya. Sedangkan kinerja menurut Robbins (2006) adalah merupakan hasil atau tingkat keberhasilan seorang secara keseluruhan selama periode tertentu di dalam melaksanakan tugas dibandingkan dengan berbagai kemungkinan, seperti standar hasil kerja, target atau sasaran atau kriteria.

2. Indikator Kinerja Karyawan
a. Menurut Robbins (2006:200) ada 6 indikator yaitu:
b. Kualitas
c. Kuantitas
d. Ketepatan waktu
e. Efektivitas
f. Kemandirian
g. Komitmen kerja

\section{KERANGKA KONSEPTUAL DAN HIPOTESIS}

Berdasarkan perumusan masalah, tujuan penelitian dan landasan teori, maka kerangka konseptual penelitian dapat dilihat pada gambar 1.

Gambar 1. Kerangka Konseptual

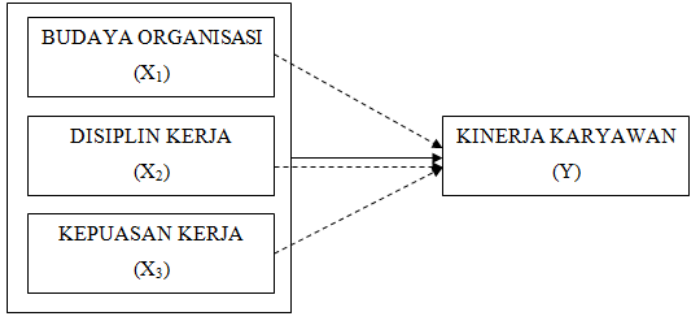




\section{Keterangan :}

$\overrightarrow{\text { Y secara simultan }}$

$\overrightarrow{\mathrm{Y}} \mathrm{-}$ secara parsial

Pengaruh variabel $\mathrm{X}$ terhadap

Berdasarkan kerangka konseptual pada gambar 1 diatas maka hipotesis penelitian ini dapat dirumuskan sebagai berikut:

$\mathrm{H}_{1}$ :Budaya organisasi, disiplin kerja dan kepuasan kerja terpengaruh secara parsial terhadap kinerja karyawan non medis Rumah Sakit Islam Malang.

$\mathrm{H}_{2}$ :Budaya organisasi, disiplin kerja dan kepuasan kerja berpengaruh secara simultan terhadap kinerja karyawan non medis Rumah Sakit Islam Malang.

\section{METODE PENELITIAN}

Penelitian ini menggunakan desain riset causa / atau sebab akibat yang digunakan untuk mennganalisa hubungan antar variabel satu dengan lainnya, menggunakan 62 respon dan sampel yaitu karyawan non medis.

Teknik pengambilan sample yaitu purposive sampling yaitu teknik pengambilan sampel dengan menggunakan kriteria tertentu. Adapun kriteria tersebut adalah karyawan non medis yang berstatus sebagai karyawan tetap.

Metode pengumpulan data dengan menggunakan observasi dan wawancara yang dibantu dengan kuisioner dengan terlebih dahulu dilakukan pengujian validitas dan reliabilitas terhadap instrument pertanyaan. Alat analistis statistic yang digunakan untuk menguji hipotesis yaitu uji t untuk mengaruh secara parsial dan uji F untuk pengaruh secara simultan. Untuk mengetahui pengaruh antara variabel-variabelnya digunakan alat analisis statistik Regresi Linier Berganda dengan alat bantu Software Program SSPS.

\section{VARIABEL PENELITIAN}

Variabel dari penelitian ini ada 2, terdiri dari variabel independen $(\mathrm{X})$ dan variabel dependen (y). Variabel independen (X) terdiri dari : budaya organisasi $\left(\mathrm{X}_{1}\right)$ adalah suatu sistem makna bersama yang dianut oleh karyawan non medis Rumah Sakit Islam Malang dan yang membedakan rumah sakit tersebut dengan rumah sakit sekitar lain; disiplin kerja $\left(\mathrm{X}_{2}\right)$ adalah kesadaran dan kesediaan karyawan non medis Rumah Sakit Islam Malang untuk mentaati semua peraturan Rumah Sakit Islam Malang dan normanorma yang berlaku; kepuasan kerja $\left(\mathrm{X}_{3}\right)$ adalah keadaan emosi yang senang atau emosi positif yang berasal dari penilaian pekerjaan atau pengalaman kerja karyawan non medis Rumah Sakit Islam Malang. Variabel dependennya (y) adalah kinerja karyawan adalah merupakan hasil atau tingkat keberhasilan karyawan non medis Rumah Sakit Islam Malang secara keseluruhan selama periode tertentu di dalam melaksanakan tugas dibandingkan dengan berbagai kemungkinan, seperti standar hasil kerja, target/sasaran, atau kriteria.
Yayasan Universitas Islam Malang pada tahun 1984 mulai membangun Rumah Sakit Islam Malang yang peletakan batu pertamanya dilakukan oleh menteri Agama waktu itu, namun karena kesulitan dana dan resesi ekonomi walaupun sudah $\pm 40 \%$ jadi tetapi tidak dilanjutkan.

Pada tahun 1994 rencana pembukaan Rumah Sakit Islam Malang diupayakan dengan melakukan renovasi bangunan sekolah madrasah yang pada sore hari juga digunakan sebagai tempat kuliah Fakultas Hukum UNISMA, lokasi tersebut terletak 500 meter dari rencana Rumah Sakit yang lama.

Rumah Sakit Islam Malang dengan lokasi baru, secara resmi dibuka oleh Bapak Ketua PBNU Bpk. K.H. Abdurachman Wahid. Yang mana dalam pidato peresmiannya beliau mengharapkan kelak Rumah Sakit tersebut menjadi rumah sakit pendidikan mahasiswa fakultas kedokteran di lingkungan N.U.

Dengan upaya perbaikan sistem kelengkapan sarana dan prasarana , maka pada tanggal 10 Juni1998 telah mendapat ijin resmi penyelenggaraan Rumah Sakit dari Departemen Kesehatan Republik Indonesia.

Gambaran umum responden : yang berjenis kelamin laki - laki 33 orang dan perempuan 29 orang, dengan tingkat usia antara 20 - 25 tahun berjumlah 10 karyawan, tingkat usia antara $>25-30$ tahun berjumlah 52 karyawan. Gambaran responden berdasarkan penelitian terakhir : 2 orang lulusan SD/MI, 3 orang SMP/Mts, 26 Orang SMA/SMK , 13 Diploma dan 18 orang lulusan S1.

Hasil pengujian validitas instrumen diperoleh hasil semua item pada setiap variabel dinyatakan Valid dan reliabel karena nilai $r_{\text {hitung }}>$ $\mathrm{r}_{\text {tabel }}$ dengan tingkat signifikan $\alpha=0,05 \mathrm{n}=62$ diperoleh $r_{\text {tabel }}=0,270$.

\section{UJI ASUMSI KLASIK}

Dengan menggunakan alat bantu software microsoft excel dan SPSS For Windows vers.16.0. diperoleh hasil sebagai berikut :

a. Uji Normalitas

Gambar 2. Hasil Uji Normalitas Data

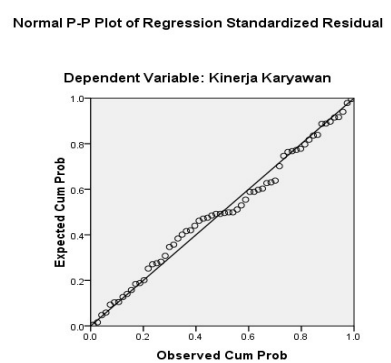

Hasil analisis menunjukkan bahwa garis yang menggambarkan data menyebar di sekitar garis diagonal dan mengikuti arah garis diagonal, maka dapat diketahui bahwa variabel kinerja karyawan , budaya organisasi, disiplin kerja berdistribusi normal atau memenuhi uji normalitas.

\section{b. Uji Multikolonieritas}


Nilai VIF dan nilai Toleransi untuk uji Multikolonieritas.

Tabel 3: Hasil Uji Multikolenieritas

\begin{tabular}{|c|c|c|}
\hline \multirow{2}{*}{ Model } & \multicolumn{2}{|c|}{ Collinearity Statistics } \\
\cline { 2 - 3 } & Tolerance & VIF \\
\hline Budaya Organisasi & .846 & 1.182 \\
\hline Disiplin Kerja & .951 & 1.052 \\
\hline Kepuasan Kerja & .823 & 1.215 \\
\hline
\end{tabular}

Sumber : Data Diolah

Metode yang digunakan untuk mendeteksi adanya Multikolonieritas dengan menggunakan tolerance and variance inflation factor (VIF). Bila nilai VIF $<10$ maka tidak terjadi Multikolonieritas dan bila VIF > 10 maka terjadi Multikolonieritas (Ghozali, 2006).

Dari tabel 3 diatas menunjukkan bahwa variabel budaya organisasi, disiplin kerja dan kepuasan kerja tidak terjadi Multikolonieritas, karena dari hasil pengujian masing-masing variabel memiliki nilai $\mathrm{VIF}<10$.

c. Uji Hekeroskedastisitas

Ada tidaknya Hekeroskedastisitas dengan melihat ada tidaknya pola tertentu pada grafik scatterplot.

Gambar : 3 Hasil uji Hekeroskedastisitas.

Scatterplot

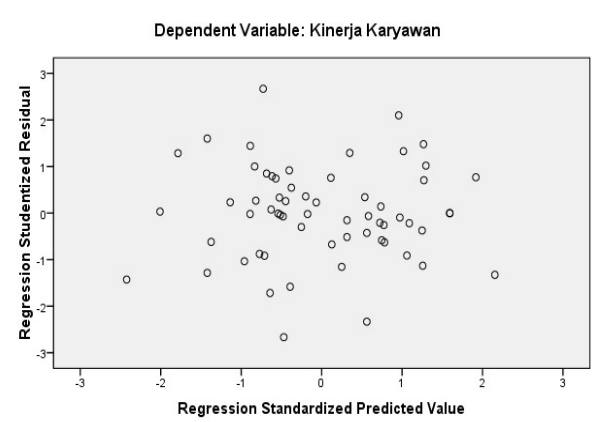

Berdasarkan gambar 3, scatterplot tersebut diatas dapat diketahui bahwa titik titik pada grafik tidak membentuk pola tertentu yang jelas, dimana titik titik menyebar di atas dan di bawah angka nol, sehingga grafik tersebut tidak bisa dibaca dengan jelas. Hasil ini menunjukkan bahwa tidak terjadi Hekeroskedastisitas.

\section{ANALISIS REGRESI BERGANDA}

Hasil analisis regresi dapat dilihat sebagai berikut $\mathrm{y}=-6.898+0,287 X_{1}+0.454 X_{2}+0.542 X_{3}$ $+7.377$

\section{UJI HIPOTESIS}

\section{Pengujian Hipotesis Secara Persial (uji t)}

Hasil uji statistik uji t dapat dilihat pada tabel dibawah ini :

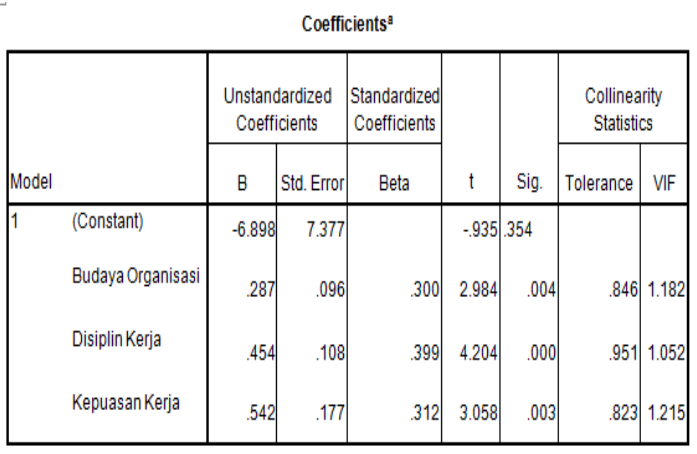

Sumber: Data Diolah

Dari hasil uji t pada tabel 4 diatas dapat dijelaskan bahwa :

a.) Variabel Budaya Organisasi $\left(X_{1}\right) t_{\text {hitung }}=$ $2,984>\mathrm{t}_{\text {tabel }}=1,671$ mempunyai pengaruh positif dan signifikan terhadap kinerja karyawan non medis RSI Malang.

b.) Variabel Disiplin Kerja $\left(\mathrm{X}_{2}\right) \mathrm{t}_{\text {hitung }}=4,204>$ $t_{\text {tabel }}=1,671$ mempunyai pengaruh positif dan signifikan terhadap kinerja karyawan non medis RSI Malang.

c.) Variabel kepuasan kerja $\left(\mathrm{X}_{3}\right) \mathrm{t}_{\text {hitung }}=3,058>$ $\mathrm{t}_{\text {table }}=1,671$ mempunyai pengaruh positif dan signifikan terhadap kinerja karyawan non medis RSI Malang.

\section{Pengujian Hipotesis Secara Simultan}

Hasil uji statistik uji f dapat dilihat pada tabel di bawah ini :

ANOVA

\begin{tabular}{|c|c|c|c|c|c|c|}
\hline Model & & Sum of Squares & $d f$ & Mean Square & $F$ & Sig. \\
\hline 1 & Regression & 478.759 & 3 & 159.586 & 19.669 & $.000^{2}$ \\
\hline & Residual & 470.596 & 58 & 8.114 & & \\
\hline & Total & 949.355 & 61 & & & \\
\hline
\end{tabular}

\section{b. DependentVariabel: Kinerja Karyawan}

Sumber : Data Diolah

Dari hasil pengujian SPSS ver. $16.0 \mathrm{di}$ atas menunjukkan hasil $\mathrm{f}_{\text {hitung }}=19,669$ dengan sig $\mathrm{f}=0.000$ dan $\mathrm{f}_{\text {table }}=2,76$. Dari nilai $\mathrm{f}_{\text {hitung }}>\mathrm{f}_{\text {table }}$ yang artinya $\mathrm{H}_{a}$ diterima, sehingga dapat disimpulkan bahwa ada pengaruh secara simultan dan signifikan antara variabel bebas budaya organisasi, disiplin kerja dan kepuasan kerja terhadap variabel terikat kinerja karyawan non medis Rumah Sakit Islam Malang.

\section{Analisis Koefisien Determinasi $\left(\mathbf{R}^{2}\right)$}

Hasil perhitungan koefisien determinasi menunjukkan hasil bahwa $\mathrm{R}^{2}$ pada karyawan non medis Rumah Sakit Islam Malang sebesar 0.504. Hal ini menunjukkan bahwa besarnya pengaruh variabel independen $\left(X_{1}, X_{2}\right.$, dan $\left.X_{3}\right)$ terhadap variabel dependen $(\mathrm{Y})$ yang dapat diterangkan oleh model persamaan ini adalah sebesar $50.4 \%$ sedangkan sisanya sebesar $49.6 \%$ dipengaruhi oleh variabel lain yang tidak diteliti dalam penelitian ini, Hal tersebut diatas bisa dilihat pada tabel di bawah ini. 
Hasil Perhitungan Koefisien Determinasi $\left(\mathbf{R}^{2}\right)$ Model Summary ${ }^{\circ}$

\begin{tabular}{|l|r|r|r|r|r|}
\hline Model & \multicolumn{1}{|c|}{$R$} & $R$ & \multicolumn{1}{|c|}{$\begin{array}{c}\text { Adjusted R } \\
\text { Square }\end{array}$} & $\begin{array}{c}\text { Std. Error of the } \\
\text { Estimate }\end{array}$ & Durbin-Watson \\
\hline 1 & $.710^{3}$ & .504 & .479 & 2.84846 & 1.722 \\
\hline
\end{tabular}

a.Predictors. (Constant), Kepuasan Kerja, Disiplin Kerja, Budaya Organisasi

\section{b. DependentVariabel:Kineria Karvawan}

Sumber : Data Diolah

\section{KESIMPULAN}

Hasil Uji Validitas dan Realibilitas dapat disimpulkan bahwa semua item setiap variabel adalah valid dan realibel karena mempunyai nilai $r_{\text {hitung }}>r_{\text {tabel. }}$. Dari hasil uji asumsi klasik diketahui bahwa variabel mempunyai distribusi normal, tidak terjadi multikolinieritas karena nilai VIF < 10 dan tidak terjadi heterokedastisitas.

Diketahui nilai $\mathrm{F}_{\text {hitung }}=19,669$ lebih besar dari $\mathrm{F}_{\text {tabel }}=2,76$ yang berarti variabel independen $\mathrm{X}_{1}, \mathrm{X}_{2}$, dan $\mathrm{X}_{3}$ secara bersama-sama (simultan) berpengaruh terhadap variabel dependen $\mathrm{Y}$, dari hasil uji $t$ menunjukkan bahwa variabel independen $X_{1}, X_{2}$, dan $X_{3}$ secara parsial mempunyai pengaruh terhadap variabel dependen Y. Dengan demikian hipotesis yang diajukan dapat diterima.

Besarnya kontribusi variabel independen terhadap variabel dependen yaitu $\mathrm{R}^{2}$ sebesar 0,504 atau 50,4\% sedangkan sisanya sebesar $49,6 \%$ dipengaruhi oleh variabel independen yang lain yang tidak termasuk dalam penelitian ini.

Dari hasil penelitian ini dapat diperoleh suatu implikasi bahwa ada pengaruh yang signifikan antara variabel bebas (hasil perhitungan uji F) yaitu budaya organisasi, disiplin kerja dan kepuasan kerja terhadap variabel terikat yaitu kinerja karyawan non medis Rumah Sakit Islam Malang. Hal ini menunjukkan bahwa apabila budaya organisasi yang ada di Rumah Sakit Islam Malang semakin baik, maka kinerja karyawan non medis Rumah Sakit Islam Malang juga akan meningkat dan menjadi lebih baik.

Jika tingkat disiplin kerja karyawan non medis Rumah Sakit Islam Malang semakin meningkat dan baik, maka kinerja karyawan non medis Rumah Sakit Islam Malang juga akan meningkat dan menjadi lebih baik. Jika tingkat kepuasan kerja karyawan non medis Rumah Sakit Islam Malang meningkat, maka kinerja karyawan non medis Rumah Sakit Islam Malang juga ikut meningkat dan lebih baik. Secara parsial semua variabel bebas berpengaruh positif dan signifikan terhadap variabel terikat yaitu kinerja karyawan non medis Rumah Sakit Islam Malang.

Perlu adanya perhatian yang lebih terhadap variabel budaya organisasi, disiplin kerja dan kepuasan kerja untuk meningkatkan kinerja karyawan non medis Rumah Sakit Islam Malang, karena variabel-variabel tersebut mempunyai pengaruh yang positif dan signifikan terhadap kinerja karyawan non medis Rumah Sakit Islam Malang. Apabila variabel-variabel tersebut tidak diperhatikan, maka bisa berakibat pada penurunan kinerja karyawan non medis Rumah Sakit Islam Malang.

\section{DAFTAR PUSTAKA}

1. Alex S. Nitisemito. 1996. Manager Personalia. Ghalia Indonesia.Jakart

2. Alex S. Nitisemito. 2000. Manajemen personalia Manajemen Sumber Daya Manusia. Ed. 3. Ghalia Indonesia. Jakarta.

3. Arikunto. S. 2002. Prosedur Penelitian. PT Rineka Cipta, Jakarta.

4. Arikunto. S. 2006. Prosedur Penelitian Suatu Pendekatan Praktik. Edisi Revisi VI. PT Rineka Cipta. Jakarta.

5. Ghozali, Imam. 2006. Aplikasi Analisis Multivariat dengan Program SPSS.Cetakan ke-6. Badan Penerbit Universitas Malang.

6. Handoko, T. Hani. 2001. Manajemen dan Sumber Daya Manusi. Liberty. Yogyakarta.

7. Hasibuan, Malayu Sp. 2005. Manajemen SDM. Edisi Revisi. Cetakan ke Tujuh.Bumi Aksara. Jakarta.

8. Hasibuan, Melayu. 2007. Manajemen Sumber Daya Manusia. Bumi Aksara. Jakarta.

9. Hasibuan, Melayu. 2010. Manajemen Sumber Daya Manusia. Bumi Aksara. Jakarta.

10. Indrianto, Supomo, 2009. Metodologi Penelitian untuk Akuntansi Manajemen.BPFE Yogyakarta.

11. Luthans, Fred. 2006. Perilaku Organisasi. Penerbit Andi. Yogyakarta.

12. Mangkunegara, Anwar Prabu. 2002. Manajemen Sumber Daya Manusia. Remaja Rosdakarya. Bandung.

13. Nasution, S. 2003. Metode Penelitian Kualitatif (Naturalistik). Gramedia, Jakarta.

14. Nitisemito, Alex. S. 2002. Manajemen Personalia : Manajemen Sumber Daya Manusia Edisi Keempat. Ghlaia Indonesia, Jakarta.

15. Prawirosentono, Suryadi. 1999. Kebijakan Kinerja Karyawan. BPFE. Yogyakarta.

16. Ridwan. 2008. Dasar-dasar Statistika. Alfa Beta. Bandung.

17. Rivai, Veithzal. 2004. Manajemen Sumber Daya Manusia Untuk Perusahaan. Cetakan Jakarta.

Pertama. Raja Grafindo Persada,

18. Rivai, Vethzal dan Basri 2005.Performance Apprasial : Sistem yang tepat untuk Menilai Kinerja Karyawan dan Meningkatkan Daya Saing Perusahaan. PT. Raja Grafindo Persada. Jakarta.

19. Rivai, Veithzal. 2011. Kepemimpinan dan Perilaku Organisasi. Edisi ketiga.Raja Grafindo Persada. Jakarta.

20. Robbins, Stephen. 2002. Prinsip - prinsip Perilaku Organisasi.Erlangga Jakarta.

21. Robbins, Stephen P., 2006. Perilaku Organisasi.PT.Indeks, Kelompok Gramedia, Jakarta. 